\title{
Analysis of Modular Teaching in Western Economics Based on Training of Practical Talents
}

\author{
Ping Wang \\ School of Yunnan Technology and Business University, Kunming, Yunnan, 651700 China
}

Keywords: practical talents; western economics; modular teaching

Abstract: In the course of western economics, students pay attention to the cultivation of students' practical ability, and attach great importance to the strengthening of students' practical skills. Therefore, in the talent training activities, based on the practical needs of cultivating practical talents, it is necessary to actively explore modular teaching in western economics teaching. The measures strive to highlight the effectiveness of personnel training, promote the comprehensive improvement of the comprehensive training ability of talents, and create conditions for the in-depth promotion of practical talent training. This paper starts with the modularization of western economics and studies the measures to cultivate practical talents, aiming to provide corresponding guidance for the reform of western economics teaching.

\section{Introduction}

The implementation of modular teaching design for the Western economics course case library is mainly to effectively improve and innovate the course teaching case. It can promote the improvement of course teaching quality based on system theory and control theory guiding ideology, and introduce modern information technology and teaching technology. Highlight the practical effects of modular teaching and create conditions for the cultivation of students' comprehensive quality. Therefore, in the process of improving and innovating Western economics teaching in combination with the needs of practical talent training, it is possible to introduce modular teaching ideas appropriately, provide relatively scientific guidance for students' learning, and create idealized for the in-depth advancement of talent training.

\section{Cultivating Western Economics Modular Instructional Design Principles Based on Practical Talents}

From the perspective of demand for practical talents, this paper analyzes the modularization of Western economics teaching design. In order to highlight the practical effects of modularized instructional design work, first-line teachers should explore specific principles and enhance the scientific nature of teaching reforms for Western economics. It lays the foundation for the scientific development of teaching and learning activities. 


\subsection{The principle of practicality}

In the process of exploring the training of practical talents, Western economics teachers should try to select the cases from the real society as far as possible to design the modular teaching, apply the case method scientifically and rationally, and use the students as the center in the teaching and organization activities. Pay attention to the highlight of student's status and the good communication and exchanges between students and students, students and teachers, let students realize their own potential in the corresponding teaching atmosphere, expand the tension of thinking in the collision of ideas, and then step by step The strengthening of their own practical ability to ensure the comprehensive enhancement of the effectiveness of personnel training [1]. In the design process of the modularization of teaching activities in Western economics, teachers can combine the case teaching with the curriculum inquiry, select the teaching plan scientifically and rationally, and combine the actual situation of the teaching case with the modular teaching. The specific requirements are to build a system that can reflect the characteristics of obvious extensibility and inclusiveness, and ensure that the modular teaching can reflect the actual situation and specific problems of economic events from multiple angles, so that the students' learning and exploration needs are met accordingly.

\subsection{The principle of overall linkage}

In order to achieve the practical effect of cultivating practical talents, we must attach great importance to cultivating talents' exploration capabilities in the course of teaching activities that aim at Western economics. Under normal circumstances, in the process of implementing modular design for teaching cases, we often attach great importance to the integration of the relevant resources involved in the system of perspective teaching case base, and then grasp the relationship and interaction between different cases to achieve The practical effect of the overall linkage teaching promotes the full implementation of practical personnel training. In the process of building a modular teaching system for teaching case bases, teachers can combine the content of the teaching to determine the basic structure of the case base and the relevant information involved in it, and assist the further advancement of teaching activities [2]. Under normal circumstances, because the socio-economic system is an objective reality and involves different subsystems, it is also necessary to conduct research and analysis from multiple angles in the modularization of teaching activities in Western economics, and to set up diversified modules. The microeconomics curriculum includes consumer behavior module, product market module, vendor behavior module, production factor market module, welfare economics module, microeconomic policy module, etc., and grasps the connection between different module theories and cases, and builds overall linkage teaching. The model will enable students to develop their inquiry skills and gradually develop students into practical talents.

\subsection{The principle of advancing with the times}

In the process of cultivating practical talents, teachers should focus on cultivating students' ability to adapt to complex economic problems and lay a foundation for their future career development. Therefore, comprehensively examining the current situation of China's economic transformation and transformation, in the process of designing modular teaching for western economics, the design of the module must ensure that it can reflect the current economic and social related elements, such as the problem of constraining the sustainable and stable development of the economy and society. The economic issues most concerned by the people and the issues affecting China's reform, opening up and the overall development of the country [3]. In the process of 
integrating modular teaching with teaching cases, we must also appropriately reflect the new changes in China's economic situation and the dynamics of new economic thinking. In the process of seeking case modules, we must pay attention to the development of students' eyes and ensure that students analyze and grasp the latest economy. The ability of phenomena and economic problems has been well cultivated, highlighting the educational ideology of advancing with the times, and thus maximizing the modularized teaching effect of Western economics and promoting the comprehensive systemic enhancement of teaching quality.

\section{Modular Teaching Practice of Western Economics Based on Cultivation of Practical Talents}

On the basis of a comprehensive and systematic analysis of the modularization of Western economics teaching, based on the practical needs of practical personnel training, in the actual reform and innovation of teaching organization activities, we have made corresponding explorations that can be practiced. The in-depth development of talent training has created ideal conditions [4]. At this stage, some schools in our country have made the following practical explorations in modular teaching based on the needs of western economics teaching.

\subsection{Case modular design according to the big theme}

In the process of constructing a modular teaching system, based on the practical needs of modular teaching, the principles involved in economic objects or economic indicators can be integrated into corresponding theme modules, and then become a large case module according to the small case teaching needs. Students' practical ability is properly cultivated. For example, in the practice exploration of teaching on GDP macroeconomic indicators, teachers can design two corresponding case teaching modules, that is, the relationship between the total GDP and the people's living conditions to improve the relationship between the module, and with the help of effective data will be The relationship between the two is fully demonstrated; the GDP growth factor module, in the process of module analysis, tries to introduce investment cases such as investment, consumption, and foreign trade that can directly affect GDP. In teaching practice, we must grasp the relationship between the two modules, and then form a new understanding of the connotation and influencing factors of GDP indicators. Through practical verification, it can be seen that in the course of explaining the content of GDP-related content, in order to promote the gradual enhancement of students' practical ability, the teacher will carry out an overall analysis of the two module teaching activities and show it to the students, which can stimulate students' learning more effectively. Interests, and on the basis of a comprehensive module to show students the information of the system, can give students a sense of shock, so that students realize the importance of the knowledge learned, and then make students a strong desire for knowledge is stimulated [5]. In the process of arranging the teaching activities, the teacher can effectively process the comprehensive case module, explain the training situation with specific knowledge points, and guide the students to analyze their actual situation, in the process of gradual exploration. The knowledge learned is organically linked, and a systematic and strong knowledge system is built to consolidate the foundation of students' practical ability training.

\subsection{Designing the case module from the perspective of time and space crossing}

In the process of designing and planning the modular case library, it is mainly for the process of many similar economic phenomena in the process of time and space shuttle. If the teachers organize the teaching activities, if these economic phenomena are brought together through the analysis of overall planning, students can form a systematic understanding of the relevant knowledge of Western economics. On the basis of grasping the laws of different cases, the students' practical ability can be 
obviously enhanced, and the students' practical ability can be promoted accordingly. For example, in the course of explaining the ups and downs of railway spring fares, based on the perspective of time and space shuttle, it can make an overall analysis of the bus and subway price hikes in the Beijing area and integrate them into a case module to guide students to weigh the land. Research on the issues of efficiency and fairness has significantly increased students' ability to apply economics knowledge to solve practical problems. Another example is that in the course of explaining the teaching of "Osters Law in China", it is integrated with the "comparison of the growth rates of employment in Brazil and China" into a unified case module, which enables students to form a new understanding of the law of Austrian affirmation. , And let students systematically interpret the relationship between the growth rate of employment and the growth rate of GDP and the factors affecting the relationship between them. In this way, we can carry out an overall analysis of different teaching cases on the basis of time and space shuttles. Based on modular teaching, we can implement more scientific and effective teaching organization guidance for students. Students' practical ability, ability to perform inferences and deductions, and comprehension by analogy can all be gradually strengthened. It has an effective role in promoting the students' practical learning effect in western economics and training students as high-quality talents [6].

\subsection{Case modular teaching design from macro and micro perspectives}

In the process of teaching and explaining the knowledge points of Western economics, teachers comprehensively analyze the practical needs of cultivating students' practical ability. They can try to combine macroeconomics cases with microeconomics cases to cultivate students' practical ability and improve them. Students' learning effects of Western economics knowledge. In the specific teaching guidance activities, teachers can study the phenomenon of economics in the process of designing a modular case base, and in the process of selecting the research entry point, they can guide students to explore from the microeconomic perspective. Interpret from a macroeconomic perspective. In terms of specific teaching organization plans, teachers can combine the corresponding teaching content to study and interpret. For example, how to systematically interpret the problem of China's civil labor shortage, using case analysis guidance can enable students to explore the basic phenomenon of China's civil work shortage from both macroscopic and microscopic perspectives, so that students can form a comprehensive understanding of this part of knowledge. From a macro perspective, the teacher guides students to analyze the labor supply problem corresponding to the salary level of the company, and combines it with microeconomics organically, as a concrete case study of the production factor market and income distribution from the perspective of microeconomics. At the same time, in the teaching activities, students can also be asked to analyze from the perspective of structural unemployment, and they can be used as an important case that can verify unemployment theory in the process of interpreting macroeconomic systems [7]. In this way, the analysis of Western economics modular teaching from the perspective of macroeconomics and microeconomics can make the students' ability to observe and analyze problems from different perspectives appropriately strengthened by the teaching activities of link relations. Under the influence of modular teaching, students' ability to integrate economic knowledge and deal with practical problems will be significantly enhanced. Students will grasp the relationship between different knowledge points in a comprehensive and systematic way in the process of learning Western economic knowledge. With the corresponding positive influence, it can promote the achievement of transformation and development of practical personnel training mode.

\section{Conclusion}

In summary, the reform and innovation of talent training based on practical talent training needs 
can fully and systematically highlight the actual effects of talent cultivation work and promote the overall improvement of the overall quality of talent. Therefore, in the process of reforming and innovating western economics teaching activities in the new era, it is necessary to further strengthen the emphasis on modular teaching, and conduct in-depth and systematic inquiry based on the reform and innovation of teaching organization activities, and deepen the training of practical talents. Advance to create good conditions.

\section{References}

[1] Feng Hua, Wang Fengyan. Reform of "Modular and Progressive” Accounting Practice Teaching Based on Applied Technology Talents Training. China Adult Education, Vol. 13(2014) No. 38, p.163-165.

[2] Qiu Zhangqiang. Research on the development of practical teaching in independent colleges based on the training of applied talents. Jiangsu Higher Education, Vol. 1(2016) No. 29, p. 76-78.

[3] Huang Sen. Reflections on the Cultivation of International Compound Economic Talents in Foreign Language Colleges__Based on the Analysis of Western Economics Teaching Reform. Industry and Technology Forum, Vol. 6(2015) No.25, p. 141-143.

[4] Zhou Chen. Exploration of Modular Teaching of Western Economics Based on Practical Talent Cultivation. Continuing Education Research, Vol. 3(2017) No.13, p. 109-111.

[5] Liu Dapeng, Xu Haiqing, Zhang Zhixin. Cultivating Applied Skilled Talents from the Application of Western Economics__Based on the Survey and Analysis of Western Economics Teaching in Dianchi College, Yunnan University. China Collective Economy, Vol. 8(2017) No.23, p. 117 -118.

[6] Xiong Yan, Bi Dongqin, Zhai Fabo. Modular Teaching Reform Practice of Drug Analysis under Applied Talents Training Mode. Modern Vocational Education, Vol. 27(2017) No.12, p. 34-35.

[7] Gao Changzheng. Combining Modular Practice Teaching to Promote the Cultivation of Applied Construction Talents. Science and Technology Vision, Vol. 8(2015) No.25, p. 31-31. 